\title{
Inhibition of experimental abdominal aortic aneurysm progression by nifedipine
}

\author{
NARUYA TOMITA ${ }^{1,3}$, KEITA YAMASAKI ${ }^{1}$, KEIKO IZAWA $^{1}$ YASUO KUNUGIZA $^{1}$, \\ MARIANA K. OSAKO ${ }^{1}$, TOSHIO OGIHARA ${ }^{2}$ and RYUICHI MORISHITA ${ }^{1}$ \\ ${ }^{1}$ Division of Clinical Gene Therapy, ${ }^{2}$ Department of Geriatric Medicine, \\ Osaka University Graduate School of Medicine, Suita 565-0871, Japan
}

Received June 27, 2007; Accepted August 10, 2007

\begin{abstract}
Agents to inhibit the renin-angiotensin system have been reported to suppress the progression of abdominal aortic aneurysm (AAA). However, the effects of calcium channel blockers (CCBs) are still unclear in terms of the inhibition of the progression of AAA. Recently, several effects of CCBs beyond those associated with blood pressure lowering have attracted much interest. In this study, we examined the effects of nifedipine on AAA progression. AAA was induced in rats by transient aortic perfusion with elastase. Then, nifedipine (10 mg/kg/day) and saline (control) were administered to rats by osmotic mini-pump. At 2 and 4 weeks, the size of the AAA, blood pressure and heart rate were measured. Then, to further explore the mechanisms of the progression of AAA, we used human vascular smooth muscle cells (VSMCs). Especially, we focused on NF- $\mathrm{KB}$ and matrix metalloproteinase-9 (MMP-9). Treatment with nifedipine resulted in a significant inhibition of the progression of AAA such as aneurismal dilation at 14 and 28 days compared to the control (week 2: control, $2.98 \pm 0.71 \mathrm{~mm}$; nifedipine, $2.37 \pm 0.64 \mathrm{~mm} ; \mathrm{p}<0.05$ and week 4 : control, $3.28 \pm 0.98 \mathrm{~mm}$; nifedipine, $2.41 \pm 0.17 \mathrm{~mm}$; $\mathrm{p}<0.05)$. Neither nifedipine nor saline changed blood pressure and heart rate, significantly. Nifedipine $(1 \mu \mathrm{M})$ significantly suppressed angiotensin II-induced $\left(10^{-6} \mathrm{M}\right) \mathrm{NF}-\kappa \mathrm{B}$ activity in VSMCs by reporter assay $(\mathrm{p}<0.01)$. Furthermore, nifedipine $(1 \mu \mathrm{M})$ inhibited MMP-9 protein expression and activity. Saline did not show such inhibitory effects. Taken together, these results indicated that nifedipine inhibits the progression of experimental AAA possibly through suppression of $\mathrm{NF}-\kappa \mathrm{B}$ and MMP-9 activity, leading to protective effects against AAA beyond those associated with blood pressure lowering.
\end{abstract}

Correspondence to: Dr Naruya Tomita, ${ }^{3}$ Present address: Division of Nephrology, Department of Internal Medicine, Kawasaki Medical School, 577 Matsushima, Kurashiki 701-0192, Japan

E-mail: tomita@med.kawasaki-m.ac.jp

Key words: abdominal aortic aneurysm, nifedipine

\section{Introduction}

Abdominal aortic aneurysm (AAA) develops in 4-8\% of men and $0.5-1.5 \%$ of women older than 50 years of age $(1,2)$. The most important complication is rupture leading to sudden death, which occurs in up to a third of patients left untreated (3). The main pathogenesis of AAA may be based on atherosclerosis. Epidemiological research has revealed that risk factors for AAA are aging, male sex, hyperlipidemia and smoking $(4,5)$. It has been reported that patients with AAA are more likely to have hypertension than patients without AAA (6). However, it is still unclear how hypertension is associated with AAA progression.

The basic phenomena in the pathogenesis of AAA are degradation of extracellular matrix components and loss of structural integrity of the aortic wall $(7,8)$. Moreover, AAA typically involves tissue inflammation as shown by the presence of inflammatory cells, which are considered to participate in the immunopathogenesis of AAA leading to destruction of the aortic matrix (9-11). Investigations have emphasized disease mechanisms involving chronic aortic wall inflammation and the progressive degradation of fibrillar matrix proteins (12). Matrix metalloproteinases (MMPs) play important roles in such mechanisms of AAA, and pathological vascular remodeling is considered to be mediated by MMPs secreted by invasive macrophages, migrating vascular smooth muscle cells (VSMCs), and endothelial cells (ECs) (13-15). The expression of MMP-2, 3, 9 and 12 was significantly increased in harvested human aneurysms $(16,17)$. These findings suggest that MMPs are strongly associated with disease activity. Some researchers have reported inhibitory effects of MMP inhibitors on the progression of experimental AAA (18-20). Moreover, we demonstrated up-regulation of the transcription factor nuclear factor $\kappa \mathrm{B}(\mathrm{NF}-\kappa \mathrm{B})$, which regulates inflammation (21). In turn, $\mathrm{NF}-\kappa \mathrm{B}$ regulates the transcription of MMP-1, 2, 3 and 9 (22-24).

Anti-hypertensive drugs, especially angiotensin-converting enzyme (ACE) inhibitors, might slow the progressive course of AAA based on studies in animals $(25,26)$. However, unfortunately, such favorable effects for calcium channel blockers (CCBs) have not been reported, and their effects are still unclear. In this study we investigated the usefulness of one of the $\mathrm{CCBs}$, nifedipine, in an experimental model of AAA. 


\section{Materials and methods}

Materials. Nifedipine was donated by Bayer Pharmaceutical Co. (Osaka, Japan). Angiotensin (Ang) II was purchased from Sigma Chemical Co. (St. Louis, MO).

Procedure involved in the AAA model. Male Wistar rats (400-500 g) (Charles River Breeding Laboratories, Osaka, Japan) were anesthetized and underwent laparotomy (19). Briefly, the abdominal aorta was isolated from the level of the left renal vein to the bifurcation. The right femoral artery was exposed, and a PE-10 polyethylene tube (Baxter Healthcare Corp., Deerfield, IL) was introduced through the femoral artery to the distal aorta. The aorta was clamped above the level of the tip of the PE tube and ligated with a silk suture near the aortic bifurcation, followed by perfusion with $0.2 \mathrm{ml}$ saline containing $50 \mathrm{U}$ type I porcine pancreatic elastase (Sigma Chemical Co.). Aortic perfusion with $2 \mathrm{ml}$ saline containing $25 \mathrm{U}$ elastase was performed for $30 \mathrm{~min}$ at $100 \mathrm{mmHg}$. One week after the operation, nifedipine $(10 \mathrm{mg} /$ $\mathrm{kg} /$ day) and saline were administered to rats by an Alzet osmotic mini pump for 4 weeks (Durect Corp., Cupertino, CA). This experiment was performed under the supervision of the Animal Committee in accordance with the Guidelines on Animal Experiments of Osaka University Graduate School of Medicine.

Ultrasonography, and blood pressure and heart rate measurement. Ultrasonography was used to demonstrate dilation of the AAA. A cardiovascular ultrasound system (Power Vision 6000, Toshiba, Tokyo, Japan) and a linear transducer (15 MHZ) were used to image the abdominal aorta noninvasively in anesthetized rats. Rats were scanned transversely to obtain images for measurement of the luminal diameter and the area of the lumen of the aneurysm at the segment with maximum diameter. The aortic size was measured before and after laparotomy once per week up to 4 weeks after the operation.

Blood pressure was measured in pre-warmed rats by the tail-cuff method (BP-98A; Softron Co., Tokyo, Japan) as previously reported (27).

Cell culture. Human VSMCs (passage 3) were obtained from Clonetech Corp. (Walkersville, MD) and cultured in $10 \%$ Dulbecco's modified Eagle's medium (DMEM) supplemented with $5 \%$ fetal calf serum. Cells were incubated at $37^{\circ} \mathrm{C}$ in a humidified atmosphere of $95 \%$ air- $5 \% \mathrm{CO}_{2}$ with medium changes every two days.

$N F-\kappa B$ reporter assay. In VSMCs $\mathrm{NF}-\kappa \mathrm{B}$ activity was evaluated using firefly luciferase reporter plasmid (pNF-кBLuc) (Stratagene, La Jolla, CA), which contains the luciferase gene driven by a promoter containing a TATA element and 3 copies of the $\kappa \mathrm{B}$ cis-acting element. Lipofectamine (Invitrogen, Carlsbad, CA) was used to transfer pNF-кBLuc into VSMCs. To induce the up-regulation of NK- $\mathrm{KB}$ activity, Ang II $\left(10^{-6} \mathrm{M}\right)$ was used in this study. Cells were collected $48 \mathrm{~h}$ after transfer, and cell extracts were prepared using the reporter lysis buffer in the Luciferase Assay System (Promega, Madison, WI). Protein content was determined using bovine serum albumin (BSA) as a standard. Luciferase values were measured by the Luciferase Assay System. The luciferase values were normalized by the protein content.

Gel mobility shift assay. Nuclear extract was prepared from VSMCs as previously described $(28,29)$. A double-stranded $\mathrm{NF}-\kappa \mathrm{B}$ oligonuclotide (ODN) probe was ${ }^{32} \mathrm{P}$-labeled with a 3 '-end labeling kit (Clontech, Palo Alto, CA) as described previously $(28,29)$. After end-labeling, the ${ }^{32} \mathrm{P}-$ labeled ODN probe was purified by Nick column (Amersham Pharmacia Biotech, Buckinghamshire, UK). Then, $10 \mathrm{ml}$ of a mixture of ${ }^{32}$ P-labeled ODN probe $(0.5-1 \mathrm{ng}, 20,000 \mathrm{cpm})$ and $1 \mathrm{mg}$ of polydeoxyinosinic-polydeoxycytidic acid (Sigma Chemical Co.) was incubated with $10 \mu \mathrm{g}$ of nuclear extracts from VSMCs for $30 \mathrm{~min}$ at room temperature prior to loading onto a $5 \%$ polyacrylamide gel. The gels were subjected to electrophoresis, dried, and the labeled DNA was visualized by autoradiography $(28,29)$.

Western blotting. Western blotting was performed for analysis of MMP-9. VSMCs were seeded onto 10-cm dishes (Corning Japan, Tokyo, Japan). Cells were collected after $48 \mathrm{~h}$ of stimulation with Ang II and were stored at $-80^{\circ} \mathrm{C}$ until extraction. After treatment, total protein was extracted with RIPA buffer (50 mM Tris-Cl, $0.15 \mathrm{M} \mathrm{NaCl}, 0.1 \%$ SDS, $1 \%$ deoxycholate, $1 \%$ Triton-X and $10 \mathrm{mM} \mathrm{NaF}$ ). Samples containing 10, 20 and $40 \mu \mathrm{g}$ protein were run on $12.5 \%$ sodium dodecylsulfate polyacrylamide gels. Proteins were separated by SDS/PAGE, transferred to a nitrocellulose membrane (Hybond ECL ${ }^{\mathrm{TM}}$ ) (Amersham Pharmacia Biotech), and incubated with a monoclonal antibody to MMP-9 (R\&D Systems, Minneapolis, MN) at $4{ }^{\circ} \mathrm{C}$ overnight. Antibodies were diluted with $4 \%$ skimmed milk and $0.1 \%$ Tween-20 in PBS. The membrane was then washed and incubated with a 1:2000 dilution of mouse or rabbit IgG horseradish peroxidaseconjugated antibody (Amersham Pharmacia Biotech). The bound antibody was detected by enhanced chemiluminescence (ECL) (Amersham Pharmacia Biotech) and Hyperfilm ${ }^{\mathrm{TM}}-\mathrm{MP}$ (Amersham Pharmacia Biotech).

SDS-PAGE zymography. Protein extracts $(30 \mu \mathrm{g})$ were mixed with SDS sample buffer (Invitrogen), and each sample was applied to $10 \%$ polyacrylamide gel containing $0.1 \%$ gelatin under nonreducing conditions. After electrophoresis, the gel was renatured in renaturing buffer (Invitrogen) for $30 \mathrm{~min}$ and equilibrated in developing buffer (Invitrogen) for $30 \mathrm{~min}$ at room temperature. After equilibration, fresh developing buffer was added, and the gel was incubated overnight at $37^{\circ} \mathrm{C}$. The gel was stained with $0.5 \%$ Coomassie blue for $30 \mathrm{~min}$ and destained with destaining solution containing $10 \%$ acetic acid and $40 \%$ methanol in distilled water. Areas of protease activity appeared as unstained bands against a blue background.

Statistical analysis. All values were expressed as the mean \pm SEM. Analysis of variance with the subsequent use of the Bonferroni/Dunnet's test was employed to determine the significance of differences in multiple comparisons. Values of $p<0.05$ were considered statistically significant. 


\section{Nifedipine}



0 week
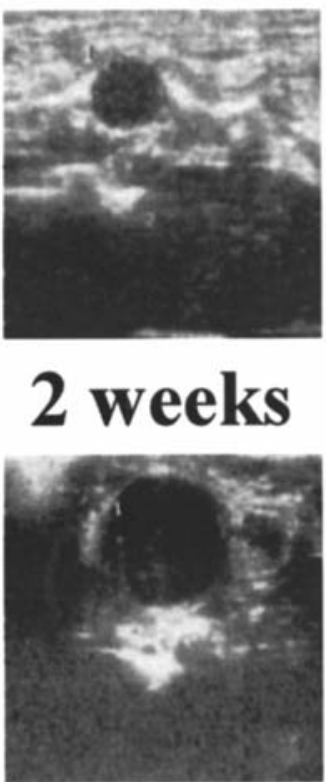



4 weeks



Figure 1. Effects of nifedipine on the size of AAA as assessed by ultrasound. Representative ultrasound images of aortic dilations are shown at each time point ( 2 and 4 weeks). Week 0 indicates the time point before administration of nifedipine and saline (control); one week after induction of AAA.

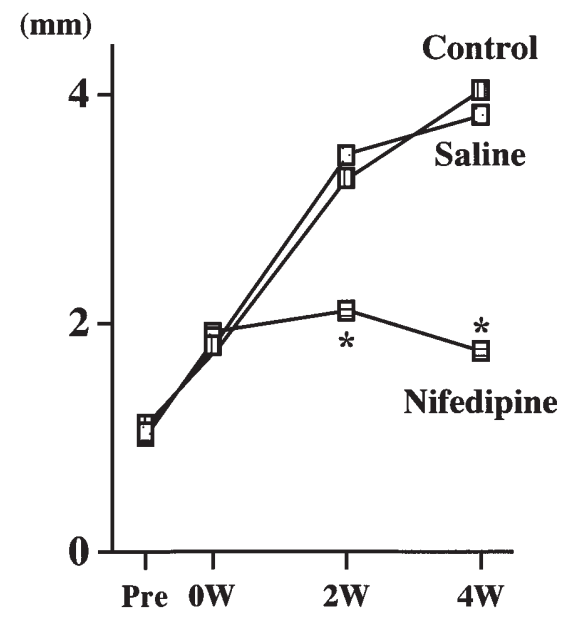

Figure 2. Time course of aortic size. Measurements were performed during ultrasound analysis. Week 0 indicates the time point before administration of nifedipine and saline (control); one week after induction of AAA. n=6/ group. Values are the means \pm SEM. ${ }^{*} \mathrm{p}<0.05$ vs. saline and control, respectively.

\section{Results}

Prevention of aneurismal dilation by nifedipine. First, we examined the inhibitory effects of nifedipine on aortic aneurismal dilation. As shown in Fig. 1, ultrasound analysis demonstrated that treatment with nifedipine prevented the progression of aortic dilation after elastase infusion. Even at 4 weeks the progression of AAA was still inhibited. To determine the inhibitory effects of nifedipine quantitatively, we measured the diameter of AAA by ultrasound. The data were consistent with the ultrasound analysis as shown in

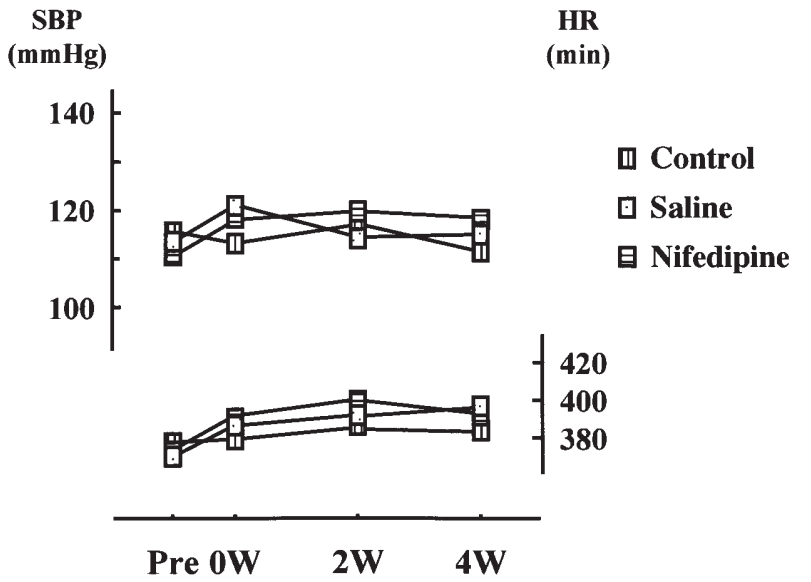

Figure 3. Changes in blood pressure and heart rate. Week 0 indicates the time point before administration of nifedipine and saline (control); one week after induction of AAA. $n=6 /$ group. Values are the means \pm SEM.

Fig. 2. Nifedipine significantly suppressed the progression of aortic dilation compared to the control groups $(\mathrm{p}<0.05)$.

We used an anti-hypertensive agent, nifedipine, at a dose that did not affect blood pressure. We selected the dose based on the results of our preliminary experiments (data not shown). In this study we also measured blood pressure and heart rate. As shown in Fig. 3, blood pressure and heart rate did not differ between the nifedipine and the control groups, as we expected.

Molecular mechanism of inhibitory effect of nifedipine. It has been reported that the transcription factor NF- $\kappa \mathrm{B}$ plays an important role in the pathogenesis of AAA (30). Therefore, we examined whether or not nifedipine affected NF- $\mathrm{KB}$ 


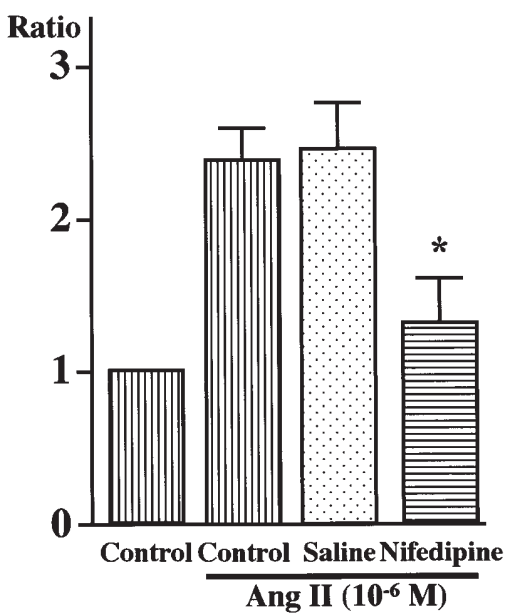

Figure 4. Effects of nifedipine and saline on NF-кB transcriptional activity in human VSMCs at $48 \mathrm{~h}$. Normalized luciferase activity to renilla activity in control cells was determined as 1.0. Relative firefly luciferase activity are shown. Five sets of experiments were performed. ${ }^{*}$ p $<0.05$ vs. saline.

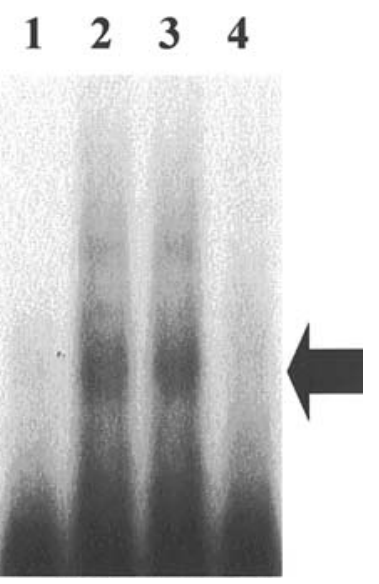

Figure 5. Representative gel mobility shift assay for NF-кB binding site. Lane 1, unstimulated control; 2, control stimulated with Ang II; 3, salinetreated VSMCs with Ang II $\left(10^{-6} \mathrm{M}\right)$; and 4, nifedipine-treated VSMCs stimulated with Ang II $\left(10^{-6} \mathrm{M}\right)$. In each lane $30 \mu \mathrm{g}$ of nuclear protein was incubated. Experiments were repeated 4 times.

activity in VSMCs. Compared with the control, nifedipine significantly decreased the expression of luciferase protein stimulated with Ang II $\left(10^{-6} \mathrm{M}\right)(\mathrm{p}<0.05)$ (Fig. 4). This result indicates that nifedipine suppresses the NF- $\kappa$ B transcriptional activity in VSMCs. To further clarify this inhibitory effect of nifedipine, we performed gel mobility shift assay. This assay also revealed that nifedipine suppressed $\mathrm{NF}-\kappa \mathrm{B}$ transcriptional activity in VSMCs (Fig. 5). In contrast, saline, the control, did not decrease NF- $\mathrm{\kappa B}$ activity. These results are consistent with a previous report by Matsumori et al (31).

Moreover, researchers have reported inhibitory effects of MMP inhibitors on the progression of experimental AAA, indicating the important role of MMPs under the regulation of NF-кB. We focused on MMP-9 in this study, because, among MMPs, MMP-9 is reported to be most important in the pathogenesis of the progression of AAA both in humans and animal models. As shown in Fig. 6, nifedipine suppressed MMP-9 protein expression as assessed by Western blot

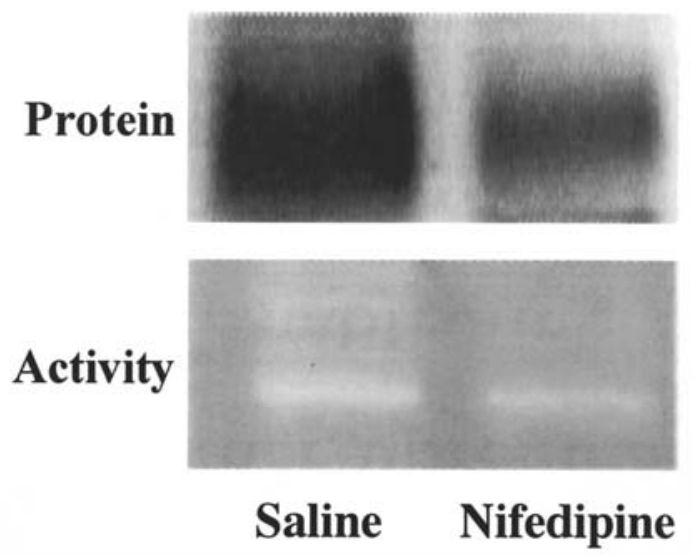

Figure 6. Representative Western blot analysis and zymography for MMP-9 Protein, Western blot analysis; activity, zymography. Experiments were performed 4 times.

analysis. Zymography also showed that nifedipine inhibited the enzyme activity of MMP-9 in VSMCs. However, these inhibitory effects on MMP-9 were not observed in the salinetreated control group.

\section{Discussion}

The incidence of AAA is increasing with aged standardized death rates having risen 20-fold in men and 11-fold in women over 30 years (32). The ageing population and improved diagnosis may account for part of this increase, however, a clear rise in the prevalence of AAA has been demonstrated. Although the increase in the rate of AAA in hypertensive patients is greater (33), it remains unclear whether hypertension is one of the risk factors for AAA. Recently, emerging evidence links the renin-angiotensin system to the development of AAA (34). Ang II is strongly up-regulated in human AAA samples $(35,36)$. Based on these reports, hypertension has become recognized as a risk factor for the development and rupture of AAA. However, the control of hypertension is often insufficient for stabilizing the aneurismal wall (37). In randomized trials of patients with AAA, the $B$-blocker, propranolol, lowered blood pressure, but it did not affect the aneurismal expansion, the need for surgical repair or mortality (38-40). Moreover, no association between B-blocker therapy and rupture has been reported (37). In experimental animal models, ACE inhibitors were substantially more effective at preventing aneurysm growth and rupture than were other anti-hypertensive agents, including $\mathrm{CCBs}$, hydralazine, spironolactone, and angiotensin receptor blockers (ARBs) $(25,26,41,42)$. ARB is a rather new class of drug, so more data based on animal and human studies should be evaluated. Thus, ACE inhibitors might be distinct in affecting the pathophysiology of AAA at present (37).

The mechanisms of AAA involve vascular inflammation related to several inflammatory cytokines, including interleukin (IL)-1, IL-6 and TNF- $\alpha(43,44)$. Human aneurismal tissues are characterized by chronic aortic wall inflammation, and the progressive degradation of fibrillar matrix proteins (12) and MMPs, including MMP-2 and MMP-9, are thought to contribute to aneurysm development (45). Also the relation of inflammation to AAA is suggested by a report 
demonstrating that monocyte chemoattractant protein-1 and its receptor, CCR-2, play an important role in Ang II-induced acceleration of the atherosclerotic process and Ang IIinduced AAA formation (46). Interestingly, a strong relationship between vascular inflammation and the progression of AAA was reported based on clinical findings $(47,48)$. Thus, hypertension might accelerate the development of AAA through inflammatory changes, since a large number of studies have reported a significant increase in the expression or activation of MMPs, intracellular adhesion molecule (ICAM) and NF- $\mathrm{KB}(49,50)$. The usefulness of ACE inhibitors in preventing the progression and rupture of AAA may be due to the fact that they have a strong effect beyond that associated with blood pressure lowering, such as an antiinflammatory effect.

In this study we focused on the $\mathrm{CCB}$, nifedipine, as one report revealed that it has a strong inhibitory effect on the activation of $\mathrm{NF}-\kappa \mathrm{B}$ in human epithelium-like lung carcinoma cells (31). A previous study showed that amlodipine, diltiazem and verapamil stimulate NF- $\mathrm{KB}$ transcriptional activity in VSMCs (51). Accumulating evidence suggests that therapeutically effective doses of CCBs activate calcium-independent signal transduction pathways altering gene expression (52-54). Thus CCBs directly activate the transcription factor NF- $\mathrm{NB}$ in human VSMCs, independently of intracellular calcium levels (51). In the present study, we demonstrated that nifedipine inhibited the activation of NF-кB in human VSMCs, which is consistent with a previous report (31). The precise explanation for this difference remains to be determined, though it has been suggested that the inhibitory effect of CCBs on NF- $\mathrm{KB}$ is apparently independent of the action on L-type calcium channels (31). Thus nifedipine may possess the unique property of inhibiting NF- $\mathrm{KB}$ independently of its calcium channel blocking activity, which may partly explain its effectiveness in the prevention of the progression of AAA in this study.

$\mathrm{NF}-\kappa \mathrm{B}$ was first identified as a regulator of the expression of the $\kappa$ light-chain gene in murine B lymphocytes (55), and has been substantially found in many different cells. It regulates the expression of several genes involved in immune and inflammatory responses (56). NF- $\mathrm{KB}$ is known to regulate the transcription of MMP-1, $-2,-3$ and -9 . Additionally, it is worth noting that the contribution of the inflammatory process is also important. In this study we observed inhibition of MMP-9 activity and protein expression by nifedipine, leading to the prevention of the progression of AAA. Taken together, these findings indicate that nifedipine exerted an inhibitory effect on the progression of AAA via the inhibition of NF- $\mathrm{B}$, resulting in a decrease in MMP-9 activity. Furthermore, in this study, nifedipine did not decrease blood pressure and heart rate. These effects were confirmed to be beyond those associated with blood pressure lowering.

In conclusion, the $\mathrm{CCB}$, nifedipine, shows potential as an anti-hypertensive drug in the treatment of AAA.

\section{Acknowledgements}

We thank Ms. Emi Nakazato for her technical assistance. This study was partially supported by grants from the Japan Health Sciences Foundation, a Grant-in-Aid from The
Ministry of Public Health and Welfare, a Grant-in-Aid for the Development of Innovative Technology, a Grant-in-Aid from Japan Promotion of Science, and through Special Coordination Funds of the Ministry of Education, Culture, Sports, Science and Technology, the Japanese Government.

\section{References}

1. Lederle FA, Johnson GR, Wilson SE, Chute EP, Hye RJ, Makaroun MS, Barone GW, Bandyk D, Moneta GL and Makhoul RG: The aneurysm detection and management study screening program: validation cohort and final results. Aneurysm Detection and Management Veterans Affairs Cooperative Study Investigators. Arch Intern Med 160: 1425-1430, 2000 .

2. Lederle FA, Johnson GR and Wilson SE: Abdominal aortic aneurysm in women. J Vasc Surg 34: 122-126, 2001.

3. Darling RC, Messina CR, Brewster DC and Ottinger LW: Autopsy study of unoperated abdominal aortic aneurysm: a population-based study. J Vasc Surg 18: 74-80, 1993.

4. Van der Vliet JA and Boll APM: Abdominal aortic aneurysm (seminar). Lancet 349: 863-866, 1997.

5. Collin J: The epidemiology of abdominal aortic aneurysm. Br J Hosp Med 40: 65-68, 1998.

6. Wilmink A and Quick C: Epidemiology and potential for prevention of abdominal aortic aneurysm. Br J Surg 85: 155-162, 1998.

7. Freestone T, Turner RJ, Coady A, Higman DJ, Greenhalgh RM and Powell JT: Inflammation and matrix metalloproteinases in the enlarging abdominal aortic aneurysm. Arterioscler Thromb Vasc Biol 15: 1145-1151, 1995.

8. Curci JA, Liao S, Hoffman MD, Shapiro SD and Thompson RW: Expression and localization of macrophage elastase (matrix metalloproteinases-12) in abodominal aortic aneurysms. J Clin Invest 102: 1900-2000, 1998.

9. Rijbroek A, Moll FL, van Dijk HA, Meijer R and Jansen JW: Inflammation of the abdominal aortic aneurysm wall. Eur $\mathbf{J}$ Vasc Surg 8: 41-46, 1994.

10. Koch AE, Haines GK, Rizzo R, Radoservich JA, Pope RM, Robinson PG and Pearce WH: Human abdominal aortic aneurysms; analysis suggesting an immune-mediated response. Am J Pathol 137: 1199-1213, 1990.

11. Brophy CM, Marks WH, Reilly JM and Tilson MD: Decreased tissue inhibitor of metalloproteinases (TIMP) in abdominal aortic aneurysm tissue: a preliminary report. J Vasc Surg 50: 653-657, 1991

12. Shark PK: Inflammation, metalloproteinases, and increased proteolysis: an emerging pathophysiological paradigm in aortic aneurysm. Circulation 96: 2115-2117, 1997.

13. Newman KM, Jean-Claude J, Li H, Scholes JV, Ogata Y, Nagase $\mathrm{H}$ and Tilson MD: Cellular localization of matrix metalloproteinases in the abdominal aortic aneurysm wall. J Vasc Surg 20: 814-820, 1994.

14. Thompson RW, Holmes DR, Mertens RA, Liao S, Botney MD, Mecham RP, Welgus HG and Parks WC: Production and localization of 92-kilodalton gelatinase in abdominal aortic aneurysms: an elastolytic metalloproteinase expressed by aneurysm-infiltrating macrophages. J Clin Invest 96: 318-326, 1995.

15. Petrinec D, Liao S, Holmes DR, Reilly JM, Parks WC and Thompson RW: Doxycycline inhibition of aneurismal degradation in an elastase-induced rat model of abdominal aortic aneurysm: prevention of aortic elastin associated with suppressed production of $92 \mathrm{kD}$ gelatinase. J Vasc Surg 23: 336-346, 1996.

16. Knox JB, Sukhova GK, Whittemore AD and Libby P: Evidence for altered balance between matrix metalloproteinases and their inhibitors in human aortic diseases. Circulation 95: 205-212, 1997.

17. McMillan WD, Tamarina NA, Cipollone M, Johnson DA, Parker MA and Pearce WH: Size matters: the relationship between MMP-9 expression and aortic diameter. Circulation 96: 2228-2232, 1997.

18. Moore G, Liao S, Curci JA, Starcher BC, Martin RL, Hendricks RT, Chen JJ and Thompson RW: Suppression of exprimental abdominal aortic aneurysms by systemic treatment with a hydroxamate-based matrix metalloproteinase inhibitor (RS 132908). J Vasc Surg 29: 522-532, 1999. 
19. Pyo R, Lee JK, Shipley JM, Curci JA, Mao D, Ziporin SJ, Ennis TL, Shapiro SD, Senior RM and Thompson RW: Targeted gene disruption of matrix metalloproteinase- 9 (gelatinase B) suppresses development of experimental abdominal aortic aneurysm. J Clin Invest 105: 1641-1649, 2000.

20. Boyle JR, McDermott E, Crowther M, Wills AD, Bell PR and Thompson MM: Doxycycline inhibits elastin degradation and reduces metalloproteinase activity in a model of aneurismal disease. J Vasc Surg 27: 354-361, 1998.

21. Nakashima H, Aoki M, Miyake T, Kawasaki T, Iwai M, Jo N, Oishi M, Kataoka K, Ohgi S, Ogihara T, Kaneda Y and Morishita R: Inhibition of experimental abdominal aortic aneurysm in the rat by use of oligodeoxynucleotides suppressing activity of nuclear factor $\mathrm{\kappa B}$ and ets transcription factors. Circulation 109: 132-138, 2004.

22. Bond M, Baker AH and Newby AC: Nuclear factor kappaB activity is essential for matrix metalloproteinase- 1 and -3 upregulation in rabbit dermal fibroblasts. Biochem Biophys Res Commun 264: 561-567, 1999.

23. Kim H and Koh G: Lipopolysaccharide activates matrix metalloproteinase-2 in endothelial cells through an NF-kappaBdependent pathway. Biochem Biophys Res Commun 269: 401-405, 2000.

24. Campbell SE, Nasir L, Argyle DJ and Bennett D: Molecular cloning and characterization of canine metalloproteinase-9 gene promoter. Gene 273: 81-87, 2001.

25. da Cunha V, Tham DM, Martin-McNulty B, Deng G, Ho JJ, Wilson DW, Rutledge JC, Vergona R, Sullivan ME and Wang Y: Enalapril attenuates angiotensin II-induced atherosclerosis and vascular inflammation. Atherosclerosis 178: 9-17, 2005.

26. Huang W, Alhenc GF and Osborne-Pellegrin MJ: Protection of the arterial internal elastic lamina by inhibition of the reninangiotensin system in the rat. Circ Res 82: 879-890, 1998.

27. Tomita N, Yamasaki K, Izawa K, Kunugiza Y, Osako MK, Ogihara $\mathrm{T}$ and Morishita R: Improvement of organ damage by a non-depressor dose of imidapril in diabetic spontaneously hypertensive rats. Int J Mol Med 19: 571-579, 2007.

28. Tomita N, Morishita R, Lan HY, Yamamoto K, Hashizume M, Notake M, Toyosawa K, Fujitani B, Mu W, Nikolic-Paterson DJ, Atkins RC, Kaneda Y, Higaki J and Ogihara T: In vivo administration of a nuclear transcription factor-kappaB decoy suppresses experimental crescentic glomerulonephritis. J Am Soc Nephrol 11: 1244-1252, 2000.

29. Tomita N, Morishita R, Tomita S, Yamamoto K, Aoki M, Matsushita H, Hayashi S, Higaki J and Ogihara T: Transcription factor decoy for NF- $\mathrm{KB}$ inhibits TNF- $\alpha$-induced IL-6 and ICAM-1 expression in endothelial cells. J Hypertens 16: 993-1000, 1998.

30. Shiraya S, Miwa K, Aoki M, Miyake T, Oishi M, Kataoka K, Ohgi S, Ogihara T, Kaneda Y and Morishita R: Hypertension accelerated experimental abdominal aortic aneurysm through upregulation of nuclear factor- $\mathrm{\kappa B}$ and ets. Hypertension 48: 628-636, 2006.

31. Matsumori A, Nunokawa Y and Sasayama S: Nifedipine inhibits activation of transcription factor NF-кB. Life Sci 67 : 2655-2661, 2000.

32. Fowkes F, Macintyre $\mathrm{C}$ and Ruckley C: Increasing incidence of aortic aneurysms in England and Wales. BMJ 298: 33-35, 1989.

33. Crownenwett JL: Variables that affect expansion rate and rupture of abdominal aortic aneurysms. Ann NY Acad Sci 800: 56-67, 1996.

34. Daugherty A and Cassis L: Angiotensin II and abdominal aortic aneurysms. Curr Hypertens Rep 6: 442-446, 2004.

35. Ihara M, Urata H, Kinoshita A, Suzumiya J, Sasaguri M, Kikuchi M, Ideishi M and Arakawa K: Increased chymasedependent angiotensin II formation in human atherosclerotic aorta. Hypertension 33: 1399-1405, 1999.

36. Tsunemi K, Takai S, Nishimoto M, Yuda A, Hasegawa S, Sawada Y, Fukumoto H, Sasaki S and Miyazaki M: Possible roles of angiotensin II-forming enzymes, angiotensin-converting enzyme and chymase-like enzyme, in the human aneurismal aorta. Hypertens Res 25: 817-822, 2002.

37. Hackman DG, Thiruchelvam D and Redelmeier D: Angiotensin-converting enzyme inhibitors and aortic rupture: a population-based case-control study. Lancet 368: 659-665, 2006.
38. Lindholt JS, Henneberg EW, Juul S and Fasting H: Impaired results of a randomized double blinded clinical trial of propranolol versus placebo on the expansion rate of small abdominal aortic aneurysms. Int Angiol 18: 52-57, 1999.

39. The Propranolol Aneurysm Trial Investigators: Propranolol for small abdominal aortic aneurysms: results of a randomized trial. J Vasc Surg 35: 72-79, 2002.

40. Wilmink ABM, Hubbard CSFF, Day NE and Quick CRG: Effect of propranolol on the expansion of abdominal aortic aneurysms: a randomized study. Br J Surg 87: 499-500, 2000.

41. Nagashima H, Uto K, Sakomura Y, Aoka Y, Sakuta A, Aomi S, Hagiwara N, Kawana $M$ and Kasanuki $\mathrm{H}$ : An angiotensinconverting enzyme inhibitor, not an angiotensin II type 1 receptor blocker, prevents beta-aminopropionitorile monofumarate-induced aortic dissection in rats. J Vasc Surg 36: 818-823, 2002.

42. Chen J, Kuhlencordt PJ, Astern J, Gyurko R and Huang PL: Hypertension does not account for the accelerated atherosclerosis and development of aneurysm in male apolipoprotein e/endothelial nitric oxide synthase double knockout mice. Circulation 104: 2391-2394, 2001.

43. Newman KM, Jean-Claude J, Hong L, Ramey WG and Tilson MD: Cytokines that activate proteolysis are elevated in abdominal aortic aneurysm. Circulation 90: 224-227, 1994.

44. Koch AE, Kunkel SL, Pearce WH, Shah MR, Parikh D, Evanoff HL, Haines GK, Burdick MD and Strieter RM: Enhanced production of chemotactic cytokines interleukin- 8 and monocyte chemoattractant protein-1 in human abdominal aortic aneurysm. Am J Pathol 142: 1423-1431, 1993.

45. Longo GM, Xiong W, Greiner TC, Zhao Y, Fiotti N and Baxter BT: Matrix metalloproteinase 2 and 9 work in concert to produce aortic aneurysms. J Clin Invest 110: 625-632, 2002.

46. Ishibashi M, Egashira K, Zhao Q, Hiasa K, Ohtani K, Ihara Y, Charo IF, Kura S, Tsuzuki T, Takeshita A and Sunagawa K: Bone marrow-derived monocyte chemoattractant protein-1 receptor CCR2 is critical in angiotensin II-induced acceleration of atherosclerosis and aneurysm formation in hypercholesterolemic mice. Arterioscler Thromb Vasc Biol 24: 174-178, 2004.

47. Norman P, Spencer CA, Lawrence-Brown MM and Jamrozik K: $\mathrm{C}$-reactive protein levels and the expansion of screen-detected abdominal aortic aneurysm in men. Circulation 110: 862-866, 2004.

48. Vainas T, Lubbers T, Stassen FR, Herngreen SB, van Dieijen-Visser MP, Bruggeman CA, Kitslaar PJ and Schurink GW: Serum Creactive protein level is associated with abdominal aortic aneurysm size and may be produced by aneurysmal tissue. Circulation 107: 1103-1105, 2003.

49. Tayebjee MH, Nadar S, Blamn AD, Gareth Beevers D, MacFadyen RJ and Lip GY: Matrix metalloproteinase-9 and tissue inhibitor of metalloproteinase-1 in hypertension and their relationship to cardiovascular risk and treatment: a substudy of the Anglo-Scandinavian Cardiac Outcomes Trial (ASCOT). Am J Hypertens 17: 764-769, 2004.

50. Rodringuez-Iturbe B, Ferrebuz A, Vanegas V, Quiroz Y, Mezzano S and Vaziri ND: Early and sustained inhibition of nuclear factor-kappaB prevents hypertension in spontaneously hypertensive rats. J Pharmacol Exp Ther 315: 51-57, 2005.

51. Hayashi M, Yamaji Y, Nakazato Y and Saruta T: The effects of calcium channel blockers on nuclear factor kappa B activation in the mesangium cells. Hypertens Res 23: 521-525, 2000.

52. Roth M, Keul R, Emmons LR, Horl WH and Block LH: Manidipine regulates the transcription of cytokine gene. Proc Natl Acad Sci USA 89: 4071-4075, 1992.

53. Rodler S, Roth M, Nauck M, Tamm M and Block LH: Ca(2+)channel blockers modulate the expression of interleukin- 6 and interleukin-8 genes in human vascular smooth muscle cells. J Mol Cell Cardiol 27: 2295-2302, 1995.

54. Walz G, Zanker B, Barth C, Wieder KJ, Clark SC and Storm TB: Transcriptional modulation of human IL- 6 gene expression by verapamil. J Immunol 144: 4242-4248, 1990.

55. Sen R and Baltimore D: Multiple factors interact with the immunoglobulin enhancer sequences. Cell 46: 705-716, 1986.

56. Kopp EB and Ghosh S: NF- $\mathrm{KB}$ and rel proteins in innate immunity. Adv Immunol 58: 1-27, 1995. 